ВОЛОКОННО-ОПТИЧНІ ТЕХНОЛОГІЇ В ІНФОРМАЦІЙНИХ (INTЕRNЕТ, INTRANET TOЩО) ТА ЕНЕРГЕТИЧНИХ МЕРЕЖАХ

УДК 004.7; 621.391

\title{
В.І. МАЛІНОВСЬКИЙ
}

\section{ОРГАНІЗАЦІЯ БАЗ ЗНАНЬ У БАГАТОКОМПОНЕНТНИХ ОПТИЧНИХ ІНФОРМАЦІЙНИХ МЕРЕЖАХ}

\author{
Вінницький національний технічний університет, \\ 21021, вул. Хмельницьке шосе, 95, м. Вінниця, Украйна
}

\begin{abstract}
Анотація. В статті розглянуті новітні підходи використання новітніх технологій організації баз знань на базі сучасних інформаційних технологій роботи із базами даних (POSTGRESQL, MONGO \{DB\}), орієнтованих на роботу з Big Data у багатокомпонентних оптичних інформаційних мережах (БКОIM). Запропоновані підходи i архітектура можуть бути використані для створення оптичних розподілених мереж нового покоління із використанням надшвидкісних каналів (Fiber Optical 5NGi Internet) і паралельними алгоритмами штучного інтелекту (AI) на базі GRID архітектури.

Аннотация. В статье рассмотрены новейшие подходы использования современных технологий организации баз знаний на базе современных информационных технологий работы с базами данных (POSTGRESQL, MONGO $\{\mathrm{DB}\})$, ориентированных на работу с Big Data в многокомпонентных оптических информационных сетях (МКОИС). Предложенные подходы и архитектура могут быть использованы для создания оптических распределенных сетей нового поколения с использованием сверхскоростных каналов (Fiber Optical 5NGi Internet) и параллельными алгоритмами искусственного интеллекта (AI) на базе GRID архитектуры.

Abstract. In article was consider the latest approaches to using the moder up to date technologies in the organization of knowledge bases witch basis on modern information data base technologies (POSTGRESQL, MONGO \{DB\}) focused on working with Big Data in multicomponent fiber optic information networks (MCFON). The proposed approaches and architecture can be used to create new generation optical distributed networks (such GRID architecture) using high-speed channels (Fiber Optical 5NGi Internet) and parallel GRID based architectural with artificial intelligence algorithms (AIs).

Ключові слова: Багатокомпонентних оптичних інформаційних мережах (БКОIM), Big Data, волоконно-оптична мережа, 5NGi Internet, штучний інтелект (AI), GRID, архітектури. DOI: 10.31649/1681-7893-2018-35-1-93-97
\end{abstract}

\section{ВСТУП}

Багатокомпонентні оптичні інформаційні системи (БКОІМ) - це універсальні мережеві технічні рішення, які базуються на принципах обробки і передачі різних за типом структурованих даних, які зберігаються і обробляються на локально - розміщених просторово (географічно) рознесених ресурсах (віддалених серверах). БКОIM $є$ різновидом GRID [1] систем із кластерним розміщенням структурованих даних і їх розподіленим обробленням. В таких мережах виникає задача впорядкування, виділення та відповідно формування запитів на вибірку даних, яка потребує вирішення за допомогою технологій розміщення баз даних (таких як POSTGRESQL, MONGO \{DB\}, та ін.), орієнтованих на роботу 3 Big Data i технологій хмарного і кластерного розміщення SAN (Storage Area Network). Переважна більшість каналів передачі інформації у БКОІМ об‘ єднана 3 каналами передачі енергії живлення всіх структурних елементів цих мереж [1,2] на апаратному рівні. Розміщення систем зберігання на сучасних носіях, таких як SSD [3] відбувається в спеціалізованих географічно рознесених Data центрах. Об'єднані в кластери. Таким чином у БКОІМ досягається можливість автономного енергетичного живлення iї складових із паралельним розміщенням великого функціоналу, різного типу конвертованого дата-трафіку i структурованих даних при використанні технологій оброблення інформації Big Data вказаними вище інструментами. Продуктивність БКОІМ набагато перевищує традиційні інформаційні мережі і знаходиться на рівні продуктивності сучасних GRID-систем і кластер них комп’ютерів (десятки і сотні TFLOPS).

\section{РОЗРОБКА ПІДХОДІВ ДО СТВОРЕННЯ ПАРАЛЕЛЬНОЇ АРХІТЕКТУРИ БКОІМ НА ОСНОВІ БАЗ ЗНАНЬ}

Існуючі архітектури БКОІМ можна розглядати як об‘ єкти у яких актуальним і перспективним представляється впровадження високоінтелектуальних систем, та методологію і підходами систем

() В. І. МАЛІНОВСЬКИЙ, 2018 
штучного інтелекту (AI), оскільки завдяки своїй складності і багатофункціональності БКОІМ потребують автономного і оперативного управляння і прийняття рішень. Завдяки інтелектуалізації БКОІМ створюються умови для системного енергозбереження, так як реалізується функції інтелектуального управління інформаційними ресурсами і високошвидкісною вибіркою/вставленням даних, а також автономним енергетичним забезпеченням (наприклад, інтерактивне управління інтелектуальним енергозбереженням і керування окремими складовими БКОІМ ).

Розглянуто варіанти побудови архітектур БКОІМ, обчислювальні структури в яких виконані на основі на паралельних оптоелектронних і оптичних архітектур (архітектурах око-процесорного типу) $[1,2]$ із використанням технологій роботи з Big Data: POSTGRESQL, MONGO \{DB $\}$ саме в цих мережах. Причому завдяки паралелізму виконання операцій контролю і обчислень досягається висока швидкодія оброблення інформації, а завдяки використанню сучасних високопродуктивних (100-200Gbit/s) волоконно-оптичного інтерфейсів і каналів зв'язку - висока символьна швидкість передачі даних. Це в комплексі дасть можливість значно підвищити швидкодію відомих розподілених GRID систем і мереж. Загальну структурну схему обчислювальної архітектури око-процесорного типу можна привести на рис. 1 [1] та розробленої загальної структури кластеру зберігання бази знань на локальних базах даних для БКОІМ (рис.2).

Але при побудові оптичних БКОІМ існує проблема: навіть з найшвидшими системами передачі і обробки інформації, в зв'язку з неструктурованістю розміщення даних, сучасні інформаційні мережі на базі яких реалізовуються БКОІМ не можуть досягнути потрібного рівня ефективності, так як час затрачений на пошук інформації в існуючих базах даних значно перевищує час необхідний для іiі обробки і передачі. Тим більше, що БКОІМ оперують з величезними інформаційними обсягами і різними базами даних.

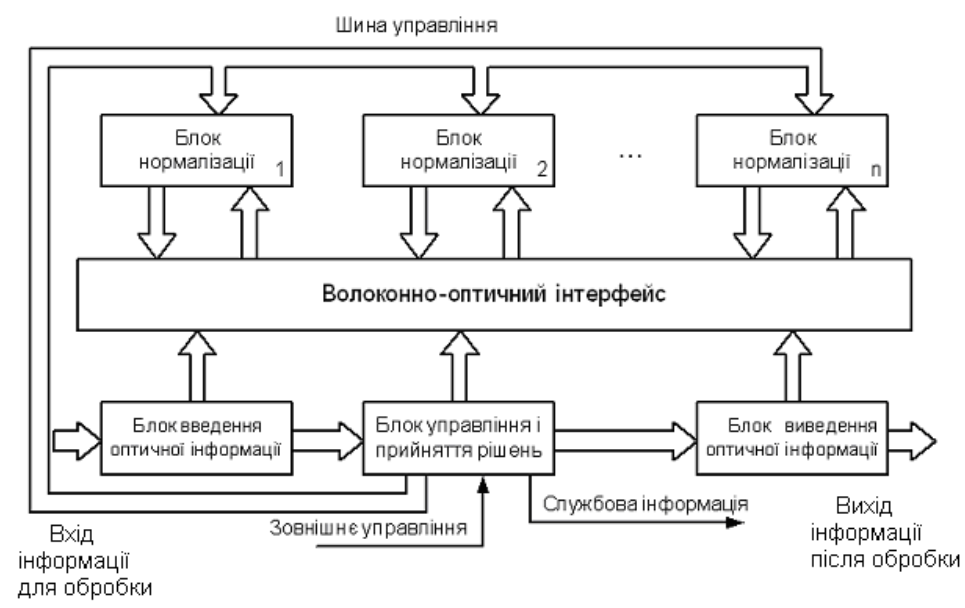

Рис.1. Загальна структурна схема обчислювальної архітектури око-процесорного типу [1]

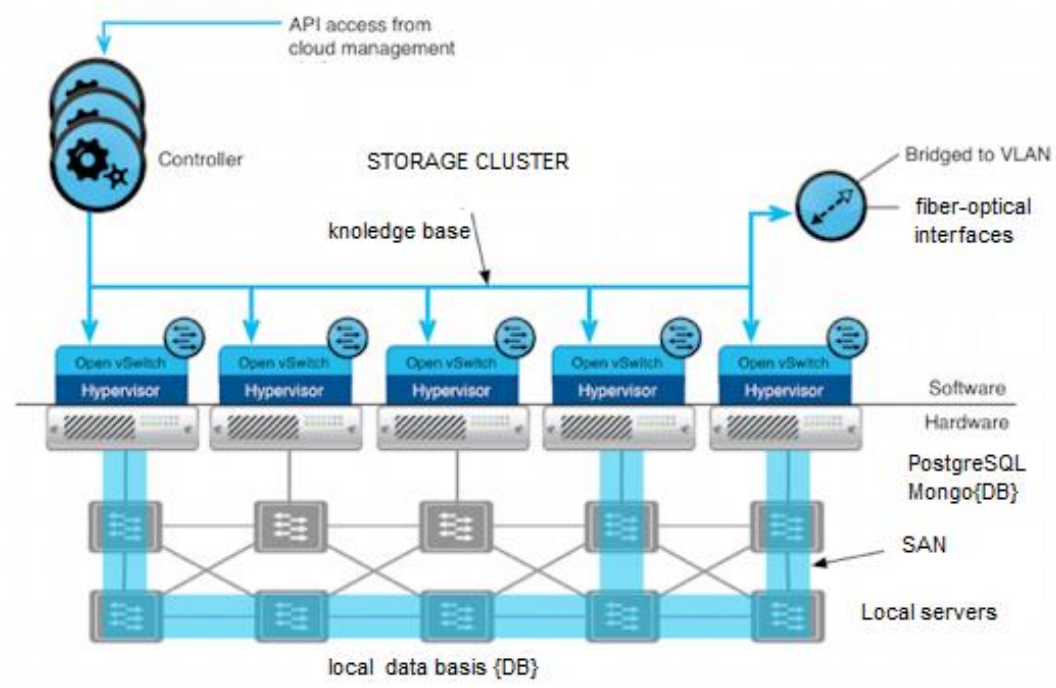

Рис.2. Загальна структура кластеру зберігання бази знань на локальних базах даних для БКОІМ 
Постає логічна проблема побудови однієї бази знань на базі структурованих баз даних із паралельною розподіленою обробкою та адаптацією сучасних алгоритмів послідовного ПЗ під ці задачі.

Хоча останнім часом для вирішення даної проблеми, яка також існує у глобальній мережі Інтернет активно почали використовувати нові програмні технології 6-7-го покоління (4 - 5 NGi Internet), але все одно цього не достатньо для досягнення необхідного рівня продуктивності і розпаралелювання обчисоювального процесу в базах даних. Вирішити дану задачу можливо за допомогою використання апаратних засобів, зокрема розміщенням структурованих за типом даних у базах знань БКОІМ. Тому необхідно підходити до рішення цієї задачі розглядаючи принцип структурованості при розміщенні інформації в базах знань і даних, як базовий і пріоритетний, так як час оперування із структурно розміщеною інформацією значно менше ніж з неструктурованою.

Можна запропонувати структурну схему блоку розміщення інформації в базі знань БКОІМ (рис.3). Завдяки використанню структуровано-збереженої інформації (відео знаходиться на сервері відеоінформації, навчальна на навчальному сервері і т.ін.) зменшується як час пошуку даних в окремих базах, так і забезпечується оптимізація управління мережею.

Так, інформація згідно свого типу зберігається на окремих ресурсах, доступ до яких реалізовується через блок формування бази знань БКОІМ, що підключений до окремих кластер них серверів. До складу цього блоку входять класифікатор, який виконує функції класифікації і визначення типу інформації, яка надійшла через зовнішній комутатор та апаратний паралельний структуризатор, що виконує функцію структуризації i упорядкування масивів баз даних на локальних серверах структурованої інформації (кластерах).

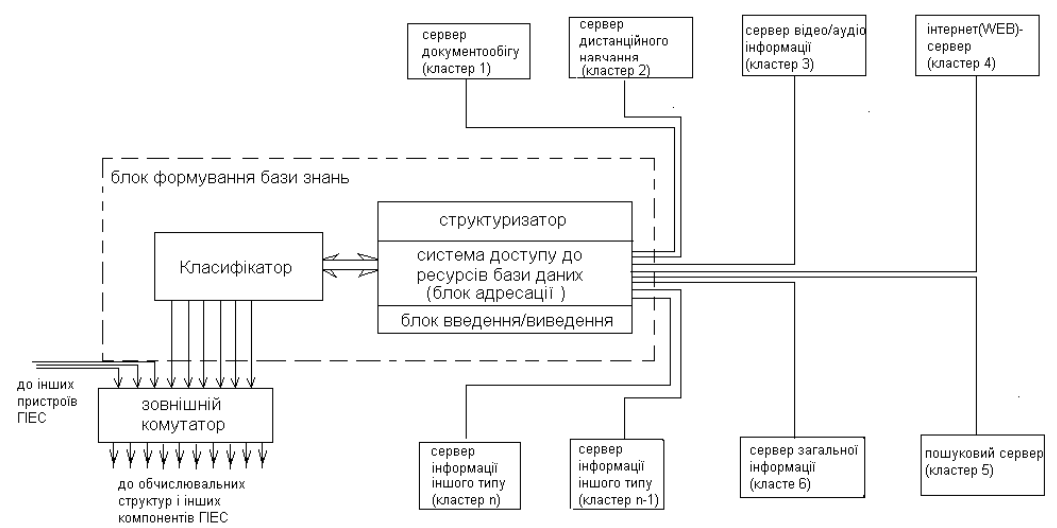

Рис.3. Структурна схема блоку розміщення інформації в базі знань БКОІМ

Кластер-це файловий сервер, їз своїм блоком обробки і операційною системою. Усі кластера (рис. 2) (i=1.n) виконані на основі архітектур око-процесорного типу (рис.1). До складу апаратного структуризатора входять система інтерфейсу доступу до баз даних, у якому формуються адреси доступу до структуризованої інформації та блок введення/виведення, що забезпечує узгодження і обмін інформацією з 1.n кластерами системи.

Такий підхід до створення бази знань (на базі окремих числених баз даних структурованої інформації) може мати місце у створеній оптико-електронній інформаційній мережі для тестування і оптимального управління інформаційними ресурсами [1] на базі GRID-архітектури (рис.4).

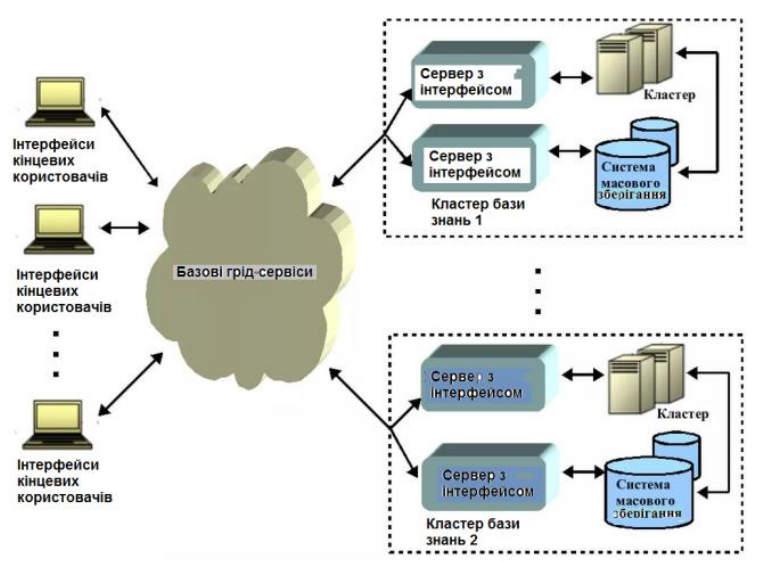


Багатокомпонентність даної мережі визначається кількістю типів даних і відповідних їм баз, а також типів інтерфейс-каналів і блоків оброблення/зберігання із відповідним функціоналом в базі знань, якими володіє дана мережа. Шляхом навчання системи база знань поповнюється шляхом створення нових елементів, кількість яких розширюється із використанням сучасних методик і технологій АI (штучного інтелекту). Наприклад, при поповненні бази знань БКОІМ для оптимального управління науково-освітянських і бібліотечними ресурсами можуть створюватись і розміщуватись нові бази даних, у загальному наборі 1.n кластерів, (який теж може розширюватись) наприклад, сформовані програми дистанційного навчання, нові результати досліджень та ін. класифікуються i структурно впорядковуються в базі знань системи.

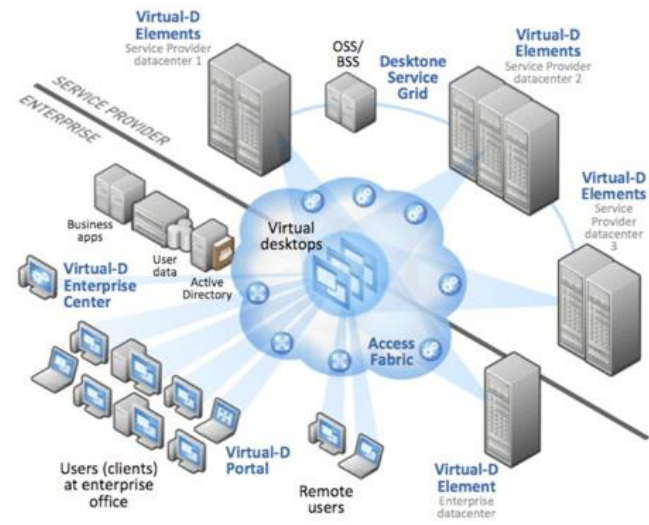

Рис.4. GRID-архітектура для БКОIМ

Використання гнучких архітектур i паралельних алгоритмів оптичних інформаційноенергетичних мереж 3 елементами управління інформаційним і енергетичним обміном дозволяє ефективно змінювати віртуальну топологію такої мережі та керувати ії функціоналом шляхом підключення нових вузлів, тим самим підвищуючи в залежності від необхідності обчислювальні і пропускні потужності мережі.

\section{ВИСНОВКИ}

Запропоновані підходи можуть бути ефективно використані для створення оптичних розподілених мереж нового покоління із використанням надшвидкісних каналів (Fiber Optical 5NGi Internet) i паралельними алгоритмами штучного інтелекту (AI) на базі GRID архітектури для надшвидкісного i гнучкого оброблення великих масивів даних Big Data.

\section{СПИСОК ЛІТЕРАТУРИ} 386.

1. E. Lach, W. Idler (2011) Modulation formats for $100 \mathrm{G}$ and beyond. Optical Fiber Technology, 17, 377 -

2. Y.K.Shah et. al. (2014). Formation and Design Considerations of Grid Architecture. Int. J Comp Sci. Emerging Tech, 5, 169-176.

3. Worldwide LHC Computing Grid. (2016). http://wlcg.web.cern.ch/ Accessed 30 November 2016.

4. Убайдулаев Р. Р. (1998). Волоконно-оптические сети. М.: Эко-Тренз.

5. В.П. Кожем'яко, О.Г. Домбровський, І.Д. Івасюк, О.В. Шевченко, С.В. Дусанюк, С.С. Білан, А.В. Кожем'яко. (2005). Оптико-електронна геоінформаційна система тотального тестування і оптимального управління науково-освітянськими і бібліотечними ресурсами для створення і розвитку централізованої бази знань. Оптико-електронні інформаційно-енергетичні технології, 1(9), 5-10.

6. В.П. Кожем“яко, Маліновський В.І.Структурна (2007). Організація каналів для повністю оптичних інформаційно-енергетичних мереж. Вимірювальна та обчислювальна техніка в технологічних процесах, 2, 37-42.

7. Кожем'яко В. П., Білан С.С., Кожем'яко О. В., Кожем'яко А. В. (2004). Оптико-електронна геоінформаційно-енергетична система, як глобальний засіб гармонійного вирішення проблем розвитку цивілізації. Оптико-електронні інформаційно-енергетичні технології, 2(8), 5-10.

8. В. Г. Олифер, Н. А. Олифер. (1999). Компьютерные сети. Принципы, технологии, протоколы. СПб: Издательство “Питер”. 


\section{REFERENCES}

1. E. Lach, W. Idler (2011) Modulation formats for 100G and beyond. Optical Fiber Technology, 17, 377-386

2. Y.K.Shah et. al. (2014). Formation and Design Considerations of Grid Architecture. Int. J Comp Sci. Emerging Tech, 5, 169-176.

3. Worldwide LHC Computing Grid. (2016). http://wlcg.web.cern.ch/ Accessed 30 November 2016.

4. Ubaydulayev R. R. (1998) Fiber optic networks. Moscow: Eco-Trentz.

5. V.P. Kozhemyako, O.G. Dombrovsky, I.D. Ivasyuk, O.V. Shevchenko, S.V. Dusanyuk, S.S. Bilan, A.V. Kozhemyako. (2005) Optical-electronic geoinformation system of total testing and optimal management of scientific and educational and library resources for the creation and development of a centralized knowledge base. Opto-electronic information and energy technologies, 1 (9), 5-10.

6. V.P. Kozhemyako, Malinovsky V.I. (2007). Structural organization of channels for fully optical information and power networks. Measuring and computing engineering in technological processes, 2, 37-42.

7. Kozhemyako V.P., Bilan S.S., Kozhemyako O.V., Kozhemyako A.V. (2004). Optical-electronic geoinformation-energy system as a global means of harmonious solving of problems of development of civilization. Optical -electronic information and energy technologies, 2 (8), 5-10.

8. V.G.Olifer, N.A.Olifer. (1999). Computer networks. Principles, Technologies, Protocols. St. Petersburg: Publishing House "Peter".

Надійшла до редакції 15.04.2018p.

ВАДИМ ІГОРЕВИЧ МАЛІНОВСКИЙ - доцент, к.т.н. кафедри лазерної та оптоелектронної техніки, Вінницький національний технічний університет, м. Вінница, Україна. 